\section{ARQUITECTURAS SIN FIN}

ARCHITECTURES WITHOUT END

Magda Mària i Serrano a los avances tecnológicos tan vigentes a inicios del si-

urante las décadas centrales del siglo $X X$, se desarrollan tanto en Europa como en América . constituidos por partes diferenciadas, utilizan estas geometrías infinitas como trazas invisibles en las que apoyar su composición. Otros, en cambio, trasladan literalmene al espacio distintas formas en espiral, de manera que estas figuras se erigen en protagonistas absolutas de proyecto.

No es de extrañar que este tipo de producciones se leven a cabo a lo largo de los años 1950 y 1960 del siglo pasado. Durante estas décadas inmediatamente posteriores a la Segunda Guerra Mundial, los progresos científicos sacan a la luz una alta cifra de descubrimientos relacionados con las micro y macroestructuras formales de la materia y el universo. Estos avances abren todo un campo de experimentación formal del que se nutren la arquitectura y las distintas disciplinas artísticas. Al mismo tiempo, la arquitectura asume un relativismo derivado de una organicidad más atenta a la naturaleza, y no tanto por parte de artistas y arquitectos y la constatación de su presencia en formas y fenómenos de la naturaleza no es exclusiva de estas décadas. A lo largo de la historia ejemplos puntuales verifican la importancia que las espirales tienen no sólo en la cultura occidental, sino en otras culturas milenarias, traspasando civilizaciones y compartiendo un similar significado simbólico: son las formas que representan la expansión energética, el crecimiento y la vida.

CIENCIA, GEOMETRIA Y ARTE: D'ARCY THOMSON Y SIR THEODORE COOK

A principios del siglo XX, los cientificos ingleses D'Arcy Thomson y Sir Theodore Cook publican por primera vez unos estudios que demuestran cómo los mecanismos de despliegue en espiral o en hélice que manifiestan muchas formas naturales son utilizados tambien en obras artistcas y arquitectónicas

El profesor de zoología escocés D'Arcy Thomson dethr limitless growth. Present in nature and elemental structures, spirals incorporate time, energy and matter in their development and have symbolised evolution and life throughout history for that reason. Their complex organizational possibilities and limitderived from them, making them dynamic, expansive and exceptional.

Persona de contacto/ Conresponding author: magda.maria@upc.edu. Escola Teecnica Superior d arquutectura del Valles. Universitat Politècrica de Catalunya
1. Thomson, D'Arcy: On Growth and Form. Cambridge: The Presss Syndicate of the University of Cambridge, 1917. Sobre el crecimiento y la forma. Madrid: Cambridge University Press, 2003. 

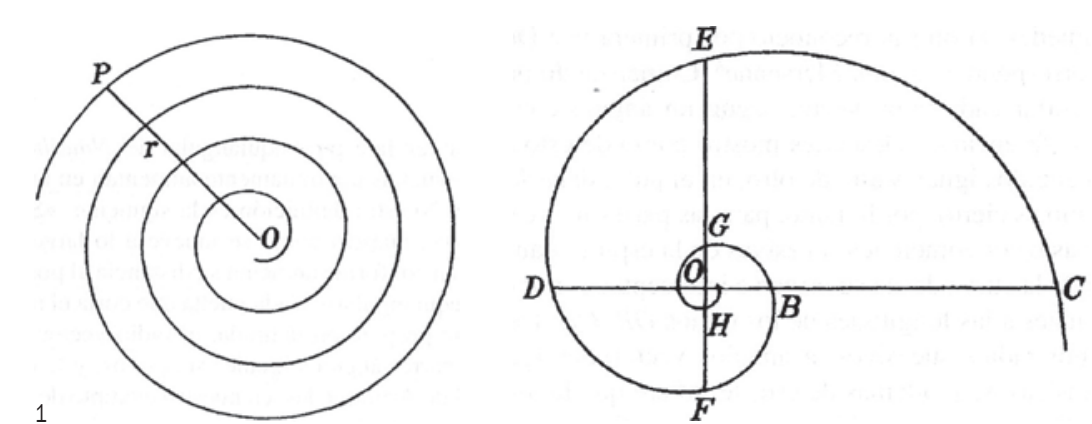

1. Esquema de las essirales uniforme 1. Escangular, segun d Arcy Thomson. 2. Andromeda nebula reproducida en 3. Illustración de portada del libro de Theodore Cook, The Curves of Life.

las espirales: son curvas que, empezando desde un punto de origen, disminuyen continuamente su curvatura al alejarse de él. Por tanto, su radio, crece sin parar Thomson distingue dos clases de espirales: la uniforme de Arquímedes y la logarímica o equiangular2 (figura 1). Esta úlima tiene un significado profundo, pues en ell se Esta representada la vida misma. el crecimiento sin fin de los procesos vitales a partir de un punto de partida un origen. En las formas naturales, las espirales logaritmicas aumentan de tamaño gracias a la materia acumulada El gran número de estructuras que presentan estos sistemas de crecimiento están constituidas por meteria segregada o depositada por células vivas. La concha del nautilus marino, la del caracol terrestre el colmillo de elefante o las uñas de un gato, crecen de forma ininterrumpida gracias al teijdo celular acumulado Y Y lo mismo sucede con las partículas que basan su reproducción en la repetición de partes semejantes, como las semillas del girasol o las esporas de una piña. Sus formas son iguales, pero difieren entre ellas en edad, magnitud y cantidad de materia que aumentan a medida que se alejan de origen.

Las propiedades específicas de la espiral logarítmica son múltiples ${ }^{3}$, pero la más relevante es la que constata que esta figura creciente incorpora el tiempo en su desarrollo. Sus giros se van ampliando de manera continua, pero lo extraordinario es que en ningún momento cambia su forma4. Tal como afirma Thomson, la espiral logaritmica, de manera analoga a la concha del caracol,

crece de tamaño al igual que la criatura que alberga pero conserva la relatividad constante de crecimiento y semeinza de forma Jakob Bernoulli el matemático sulzO que durante el siglo XVII consigue formularla por vez primera, ordena grabar sobre su tumba una espiral junto siguiente epitafio: "eadem mutato resurgo"5, que significa, "a la vez cambio y resurrección". Las cualidades de este desarrollo formal quedan así concisamente idenfificadas: el continuo cambio basado en el renacimiento simultáneo de la misma forma. En esta misma linea culturas primitivas adoptan las espirales como signos de fecundidad $y$ por tanto, de origen de vida ${ }^{6} Y$ la tradición cristiana utiliza las espirales presentes en las conchas de los moluscos como símbolo de la resurrección. Desde tiempos inmemoriales se introducen en los féretros de los difuntos conchas de caracol, pues éstas son el emblema del cuerpo humano que encierra en una envoltura exterior el alma que da vida al ser, representada por el cuerpo del molusco?

En su representación espacial, la espiral logarítmica se asemeja a un cono que se enrolla sobre sí mismo En cambio, la espiral uniforme o de Arquímedes es comparada con la manera como un marinero enrosca una cuerda sobre la cubierta de un barco. Si la cuerda tiene un grueso uniforme, cada vuelta va resiguiendo el diámero de la curva precedente

El libro de Thomson se presenta como un magnifico estudio en el que se relacionan tres disciplinas apa2. La espirial logartmica fue reconocida por primera vez por Descartes y discutida publicamente en 1638 . 3. Las propiedades especificas de la espiral logaritmica o equiangular están relacionadas unas con otras: los radios vectores, los ángulos, o los sectores cor

4. "Si, en lugarar de desplazarse con una velocidad uniforme, nuestro punto se mueve a lo largó del radio vector con una velocidad que se incrementa conforme

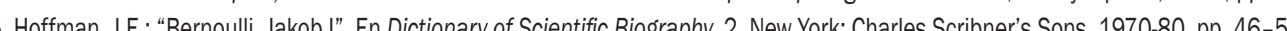

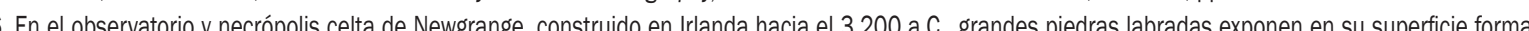
espirales, simbolo de la fecundidad. 7. Charbonneaux-Lassay, Louis: Le Bestiaire du Christ. La mystérieuse emblématique de Jés
Gaston: La poética del espacio. Madrid: Fondo de Cultura Económica, 1965, pp. 140-170. 8. "Si, mientras el radio vector gira uniformemente alrededor del polo, un punto se desplaza con velocidad uniforme sobre él, la curva descrita se llamarr
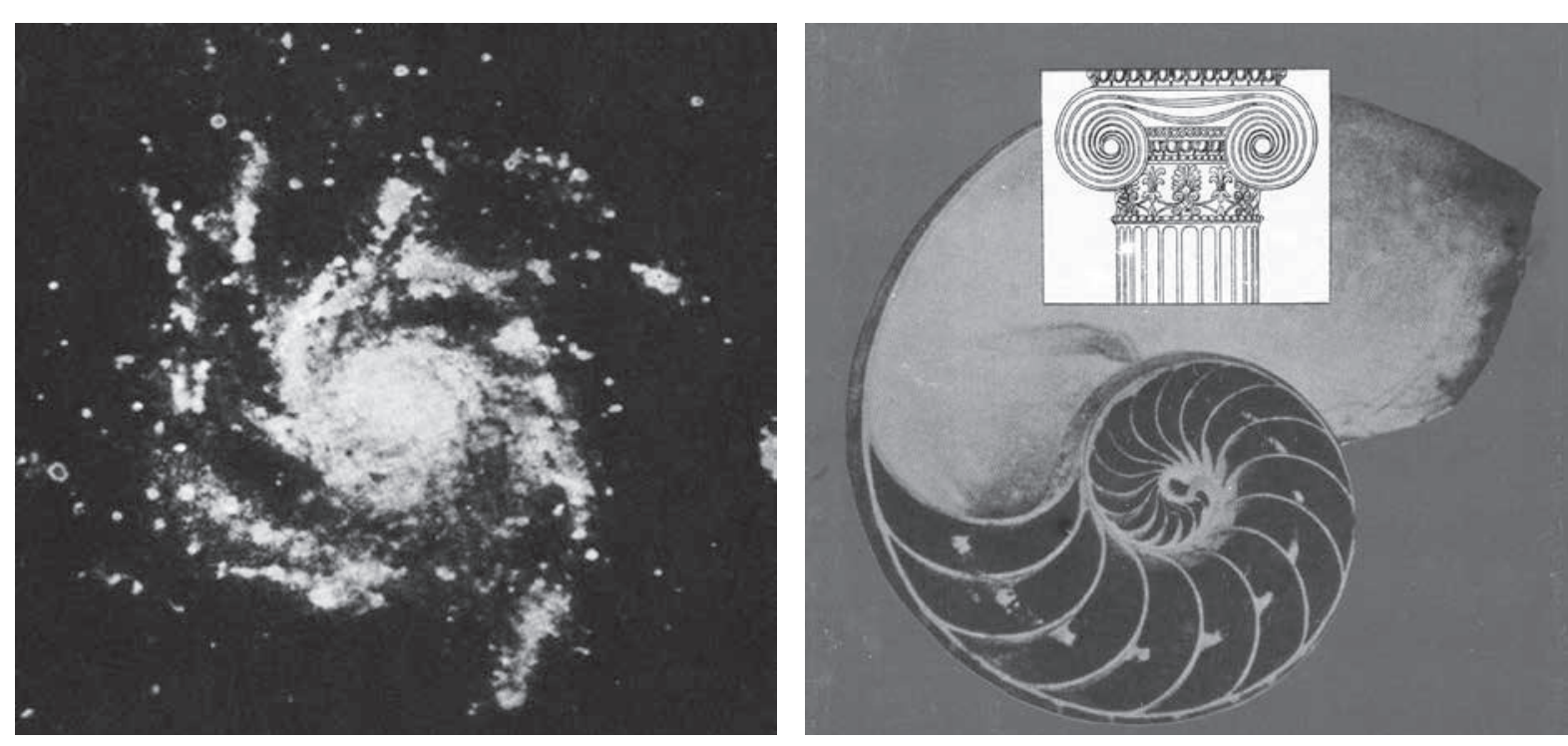

y la zoología. Pero este trabajo integrado tiene un claro precedente en el libro publicado en 1914 por Sir Theodore Cook: The curves of life'. Cook demuestra que la formación de espirales y hélices se encuentra íntimamente conectada con los mundos orgánico, inorgánico y microscópico. En el primero, estas formas aparecen en la estructura de plantas, moluscos, conchas, invertebrados, cornamentas, colas de mamíferos y, también, en el cuerpo humano. En el segundo, espirales y hélices se manifiestan en fenómenos eléctricos y de expansión energétca como remolinos y tornados; en astronomía, aparecen en nebulosas como la andrómeda nebula (figura 2). En tercero, la doble hélice del ADN, las estructuras orgánicas de crecimiento celular y la periodicidad de los elomentos atómicos, son ejemplos significativos

Al mismo tiempo, Theodore Cook relaciona estos fenomenos con las teorías artísticas que argumentan la be leza pues, según él, el arte interpreta a la naturaleza, de la cual forma parte. La misma imagen que acompaña la portada de su libro superpone el dibujo de un capitel jónico a la fotografía del interior de la concha de un nautilus (figura 3). Y en el capítulo dedicado a los elementos arquitectónicos en desarrollo espiral, columnas helicoidales o escaleras de caracol tan significativas como la del castillo

de Blois, atribuida a Leonardo da Vinci'io, son comparadas de manera morfológica, matemática y constructiva con organismos naturales: principalmente con conchas de moluscos o tallos vegetales. En este sentido, la utilización de la espiral en base fi -la ratio de Phidias-, llamada ambién número de oro, sección áurea o divina proporción, se revela como una suerte de llave que explica este gran número de fenómenos naturales relacionados con el crecimientoy al mismo tiempo garantiza su aplicación sticas y arquitectónicas

Cook también reproduce en su libro un compendio de esquemas en los que se obsena por una perte, el crecimiento y la reproducción de los ćŕrculos siguiendo diversos desarrollos en espiral y, por otra, se atestigua la deuda que tienen estas reproducciones crecientes de unidades circulares con la serie de Fibonacci (figura 4). Un orden creciente de círculos similares que, como sucede con las semillas del girasol o las esporas de la piña, acumulan superficie a medida que se alejan del origen. Estos gráficos publicados por Cook ofrecen la posibilidad de aplicar crecimiento en espiral de dos maneras distintas: mediane un conjunto de formas similares que van aumentando de tamaño, librando un vacío en el punto donde se origina su nacimiento, 0 a traves de una linea vertebradora

9. Cook, Theodore: The Curves of Lifie. London: Constable and Company, 1914. New York: Dover Publication, 1979. Este libro tiene un precedente en un ensayo publicado por el mismo autor en 1903. Ver: Cook, Theodore: Spirals in Nature and Art. London, 1903.

10. Leonardo da Vinci es uno de los artistas que, de manera premonitoria, observa la presencia de espirales y hélices en la naturaleza, trasladánnolas a su

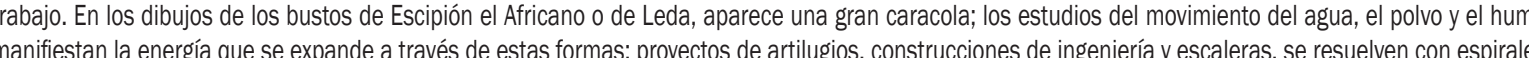
hélices. Entre las escaleras más conocidas atribuidas a Leonardo se encuentran las de los castillos de Bloise y Chambord. Ver: Pedretti, Carlo: Leoonardo architetto. Milano: Electa, 1978, pp. 247.

11. Siguiendo la estela de los libros de d'Arcy Thomson y Theodore Cook, Mathila Ghika publica una deccada después Estetica de las proporciones en la natura

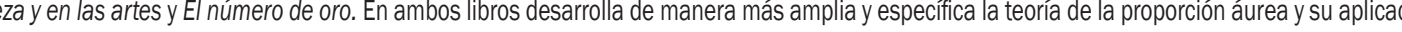


4. Esquemas de crecimiento $3+5 y$ yrect miento eirch 5. Joseph En
1939. Plantas. 6. Frank Lloyd Wright, Ralph Jester House, 1938- 40. Planta.
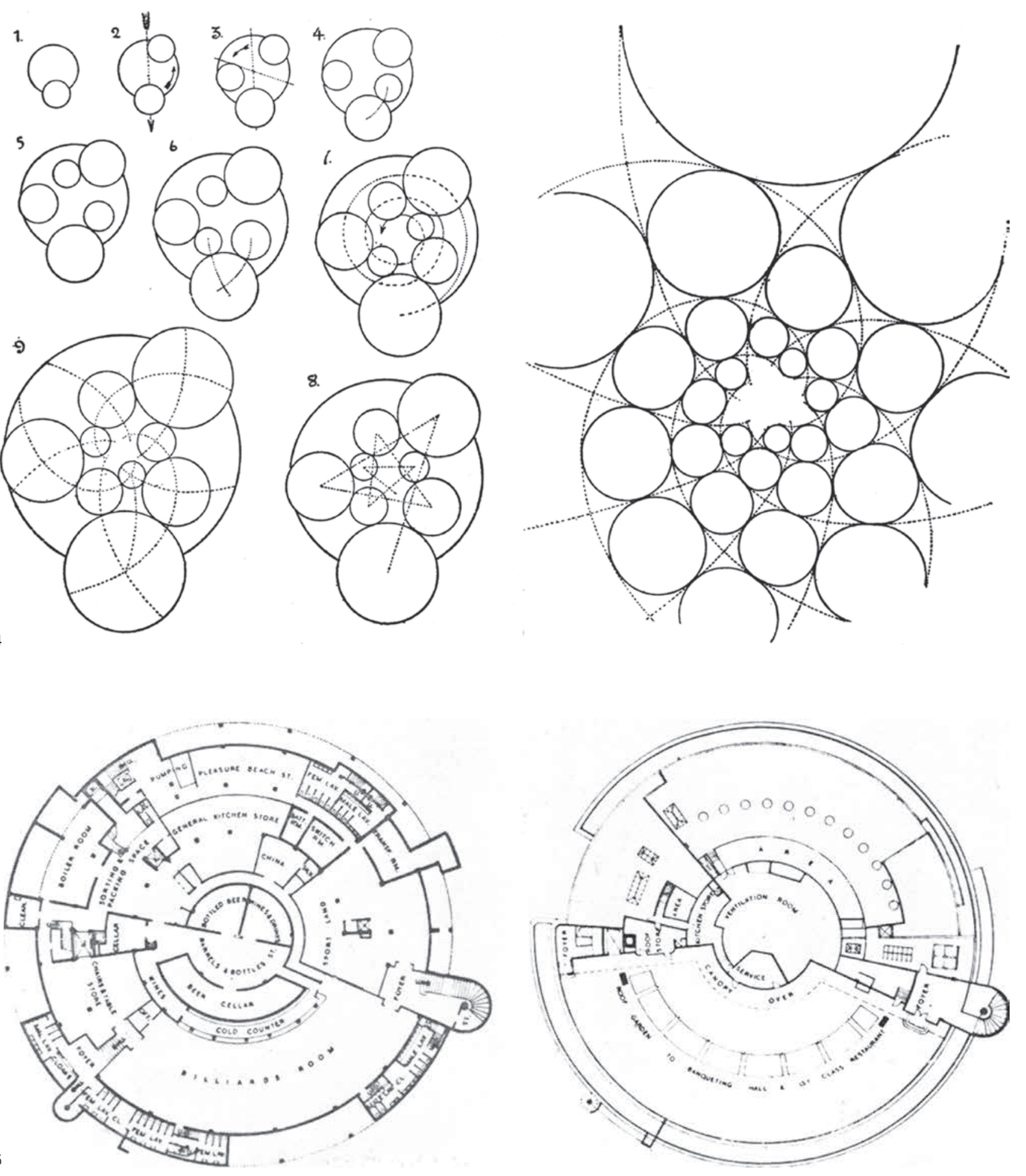

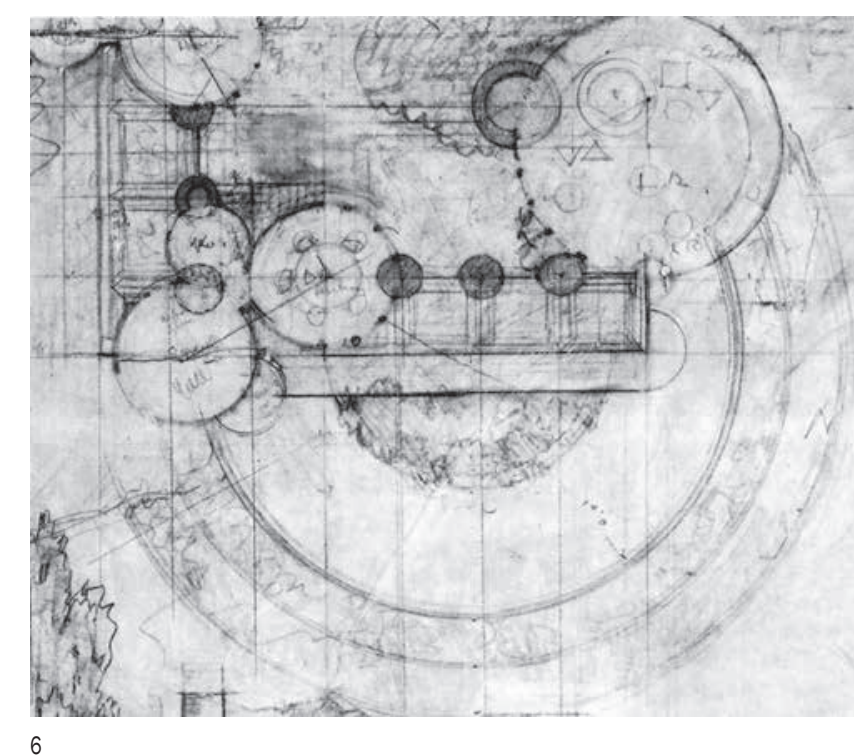

continua que sigue la fuerza motriz de la expansión. Será precisamente la combinacionde estas dos opclones, con sus múltiples variables, la que aplicará la arquitectura de mediados del siglo XX en algunos proyectos ejemplares.

TRAZAS ESPIRALES Y FORMAS SIMILARES EN

ARQUITECTURA: EMBERTON Y WRIGHT

Dos décadas después de la aparición de estas publicaciones, el arquitecto y teorico inglés Joseph Emberton (1889-1956), utiliza directamente uno de los diagramas de Cook para proyectar y construir el casino de Blackpool (1933-1939)'2. Aunque sus obras arquitectónicas se identifican con la estética y las ideas del movimiento racionalista ingles, Emberton es pionero en su generación en aplicar esquemas dinámicos a la arquitectura Siguiendo el esquema de crecimiento $3+5$ reproducido por Cook, utiliza la misma dispersión controlada de formas circulares que van aumentando logartmicamente de lamano para organizar, en este casino, todas las partes del programa (igura 5). De hecho, en la memoria del proyecto adjunta los mismos esquemas de crecimiento que el naturalista y matemálico ingles utiliza en su libro The curves of life, sobre los que dibuja a lapiz la linea de crecimiento espiral que une los centros de las distintas circunferenclas. De manera analoga a estos diagra vacío que coincide con el origen de la expansión formal.

El edificio finalmente construido en Blackpool, circunscrito por otro gran círculo, no expresa exteriormente la dispersión controlada de circunferencias presentes en ex esquema de Cook. Sin embargo, la iniciativa de Emberton resulta fundamental para entender un reducido, pero no por ello menos significativo, número de proyectos de alguno de los principales arquitectos de su época.

Coincidiendo con el diseño y la construcción del edificio de Emberton, desde mediados de los años 30 de siglo pasado, Frank Lloyd Wright desarrolla de manera puntual diversos proyectos basados en sistemas de crecimiento continuo. Como en la planta del casino de Blackpool de 1933 y, de manera análoga a los esquemas del libro de Cook de 1914, Wright utiliza en sus composiciones un conjunto de circunferencias que se organizan siguiendo el trazado hipotetico de una espiral. Esta figua, por tanto, constituye el soporte virtual de las partes del proyecto, la estructura dinámica que permite el crecmiento y la anexión de direrentes partes circulares.

En la Raliph Jester House, proyectada en 1938 y exhbida en elMOMA de Nueva York en 1940, un conjunto de circulos de tamanos distintos se yuxtaponen o intersecan distribuyéndose por la parcela como si fueran pabellones dotados de funciones afierentes. Las distintas partes de la vivienday su particular mobiliario se insertan sin problemas en el interior de los circulos, pues están proyectadas para construirse en contrachapado de madera, un material fácilmente adaptable a la curvatura. El conjunto se deposita parcialmente dentro de un doble circulo mayo que, por un lado penetra en la casa y hace las funciones de piscina y, por orro, encadena vilualmente los distintos pabellones, de modo parecido a los esquemas de Cook (figura 6). Los cuerpos en forma de conchas o platillos volantes de tamaños diversos del Play Resort and Sports Club de Hollywood (1947) conviven tambien con platayen de manera centrípeta desde un eje central, flotando

12. Emberton manifiesta de manera explíita, tanto en sus obras escritas como en sus edificios, su interés por temas tan diversos como la ética y la estética la forma y la proporción. Entre sus libros de referenciia a los que alude constantemente se encuentran tifulos tan significativos como Dynamic Symmetry a e's Harmonic Unity de Samuel Colman y, por supuesto, The curves of life de Sir Theodore Cook. Ver. The Greek Vase. Yale Univesty

13. Ind, Rosemary: Emberton. London: Scode Press, 1983 

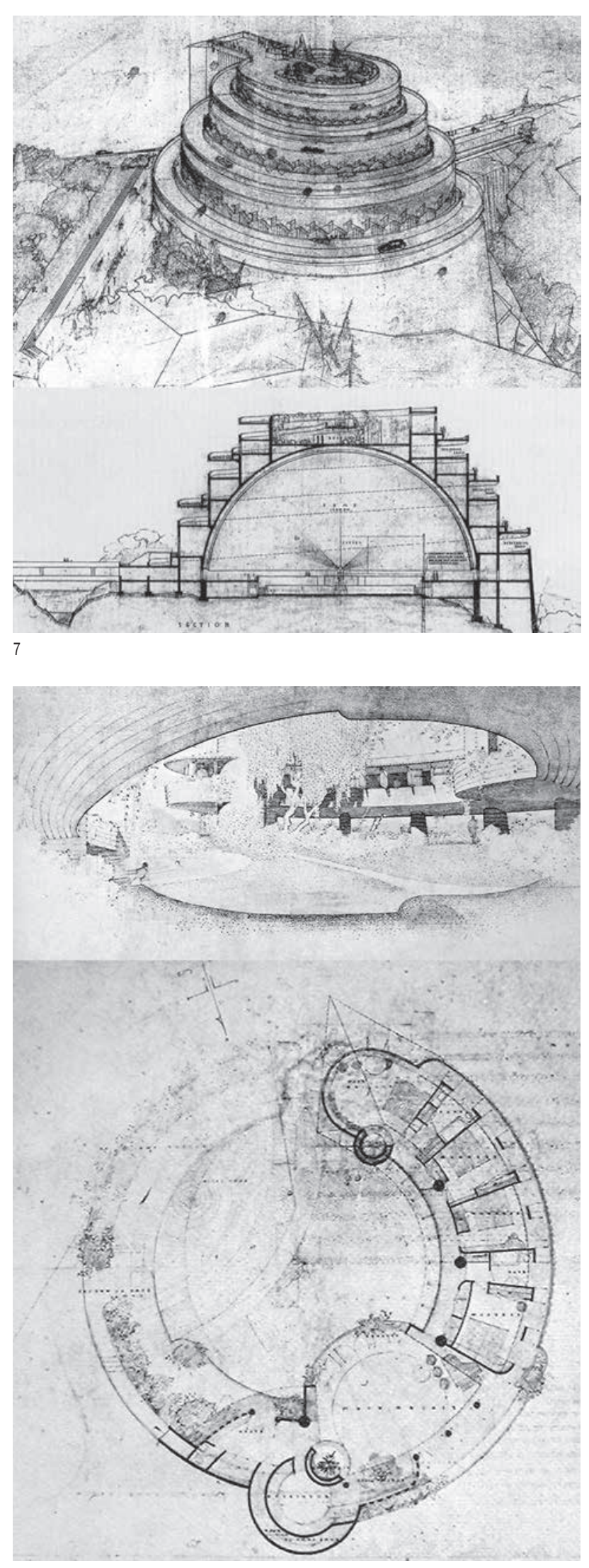

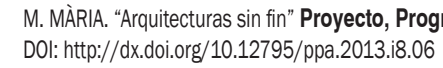

7. Frank Lloyd Wright, Gordon Strong Plane-
tarium, 1925. Perspectiva y sección. 8. Frank Loy Wrisetiva y sección. Phoenix, 1950. Planta superiory yerspeest va interior patio. sobre el terreno como si fueran orbitales. En la torre de los laboratorios Johnson (1944-50), el núcleo central se descompone en varios círculos crecientes que albergan escaleras, ascensores y servicios.

La voluntad experimental de Wright con las formas espirales surge de manera premonitoria en las propuestas de 1924-25 para el Gordon Strong Planetarium una suerte de observatorio astronómico que no llega a construir, compuesto interiormente por una gran cúpula hemisferica sobre la que se apoya una gran rampa exterior que va disminuyendo de radio de curvatura a medida que va ascendiendo. Su función es doble: el interior se utiliza como planetario, teatro y sala de proyecciones; y el desarrollo espiral exterior posibilita la circulación de los automoviles para, desde la cumbre, observar los astros y adorar a la naturaleza (figura 7). La imagen de este proyecto, similar a los ziggurats babilonicos o a las representaciones pictoricas de la Torre de Babel'14, queda latente en la memoria de Wright, pues los primeros bocetos para el Museo Guggenheim de Nueva York de 1944 son muy parecidos a este observatorio.

Durante las primeras décadas del siglo XX, diversos arquitectos contemporáneos a Wright utilizan interpretaciones parecidas del esquema formal y funcional del ziggurat en algunos proyectos significativos. Vladimir Tatlin, Albert Kahn, Friedrich Kiesler, Konstantin Melnikov o Le Corbusier, proyectan o construyen grandes artefactos ar thiciales configurados por recoritios espirales exteriores que permiten transitar hasta su cumbre $\mathrm{e}^{15}$. Pero para e arquitecto norteamericano, esta imagen se convierte en un tema recurrente a lo largo de toda su trayectoria profesional, aplicado más adelante en varios proyectos. Entre otros, destacan la organización del Community Center de Pittsburg (1947) o la manipulacion de la topografía de The A A difeerych A diferencia de estas propuestas más explícitas en las que el desarrollo espiral hace las funciones de estructura, circulación y fachada del edificio, en otras construcciones más complejas de estos anos, Wright aplica de manera simultanea los dos sistemas espirales dibujados por $\mathrm{Em}$ berton sobre el esquema de Cook: la dispersión atomizada de circulos en crecimiento logaritmico, y el trazado que se desarrolla alrededor de un espacio vacío circular central. El resultado de esta combinatoria son edificios generalmente autistas, formados por piezas perimetrales volcadas a un centro proporcionalmente mayor por el que discurre una rampa o escalera helicoidal que las conecta En el proyecto de 1941 para la Burlingham House de E Paso (Texas), o en la casa de su hijo David en Phoenix (1950-52) (figura 8), una rampa recorre perimetralmente un gran patio circular abierto, descendiendo o ascendiendo hacia las diferentes partes de la vivienda, enterradas o
elevadas respecto al terreno.

Otro ejemplo significativo de esta manera de operar más compleja en base a un desarrollo espiral es el interio de la Moris Gitt Shop de San Francisco (1948). En este exquisito establecimiento comercial, Wright se desmarca de los constrenimientos roctangulares cel solar e inserta en la parcela dos circulos tangentes de medidas distintas, que albergan dos ámbitos de diferente carácter. El circulo mayor, más público, acoge una rampa perimetral que pria un gran vacio en el centro. El ciculo monor, más

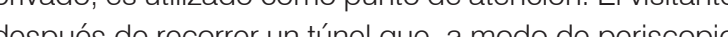
lo conduce haci der por la rampa conto desde la calle, puede ascenodos los objetos expuestos en la perifria y percibindo l mismo tiempo, la tolildad del espacio. El interior convierte gracias a estavivencia dińmica. enun sistema

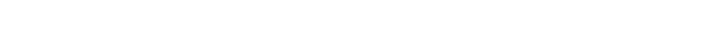

14. Las Versiones más conocidas de la Torre de Babel son las del artistata holandés Peter Brueghel el Viejo (1563). Pintores fllamencos anónimos representan

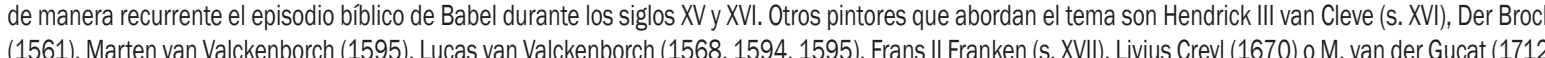

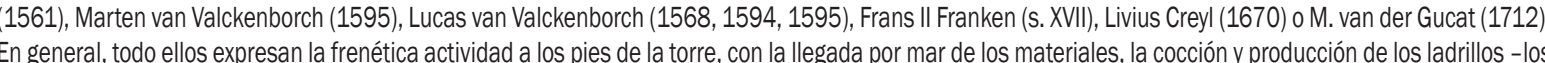
mismos materiales que los ziggurats, el labrado de las piedras, yel transporte de los materiales por las rampas hasta una cumbre todavía inacabada. Otras pinturas ya muestran la torre abandonada o en ruinas.

15. Uno de los proyectos en espiral ascendente inmediatamente anterior a la propuesta de Wright es el monumento a la III Internacional de Vladimir Tatin de 1920. De altura similar a la Torre Eiffel y pensado en hierro para la estructura externa y cristal para las salas suspendidas en el vacío interior, nunca llega constrtuirse. De este colosal proyecto óllo restan las imágenes de una maqueta de unos 7 metros de altura. Ver: Lodder, Christina: Russian Constructivism.

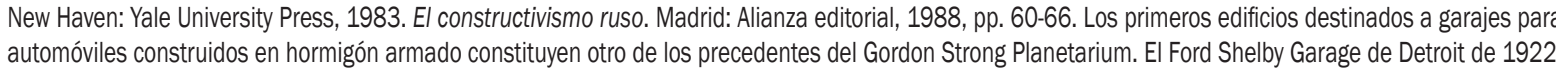
es mostrado por su autor, Albert Kahn, a Wright. En 1926, H. E. Youngy E. Taylor realizan el proyecto de un enorme edificio para coches, resuelto en su 20 na central por una doble rampa en espiral. Ver: The Guggenheim. Frank Lloyd Wright and the making of the Modern Museum. New York: Solomon R. Guggenheim Foundation, 2009, pp. 40-41. En 1924 Friedrich Kiesler construye el Theater Tecnick en Viena, desarrollado en una espiral ascendente y en 1925 proyecta una ciudad en espiral. Ver: Bogner, Dieter: Friedrich Kiesler. Architekt Maler Bildhauer 1890-1965. Wien: Löcker Verlag, 1988. En 1925 Konstantin Melnikor

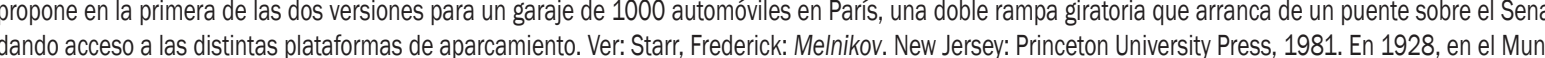
daneum de Ginebra, Le Corbusier elige un desarrollo espiral de base cuadrada, similar a un ziggurat, para renovar radicalmente la ideat tradicional de mused.

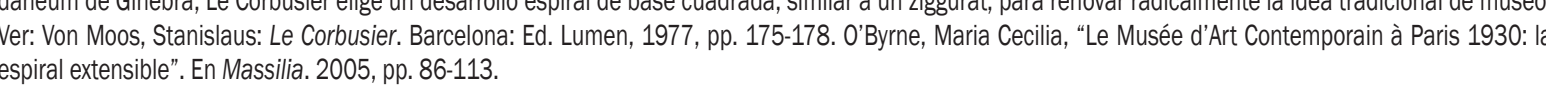

con gran potencia formal. Los planos ininterrumpidos en esin ando onirico dotado una nave espacial y la recreación de un mundo submari. El aulismo del espacio interior respecto al exterior es sarrollo envolvente de la espiral (figura 9). última etapa, Wright utiliza para las distintas versiones de Cook: los círculos que se desarrollan con tamaños difeentes, van expandiéndose de forma centrípeta. Este siscuadrada y circular que se emplea para controlar el desparrollo espacil aumentando el grado de complejidad intio a de artificiales de formas bulbosas y antropomórficas, contriabicación de las diferentes 

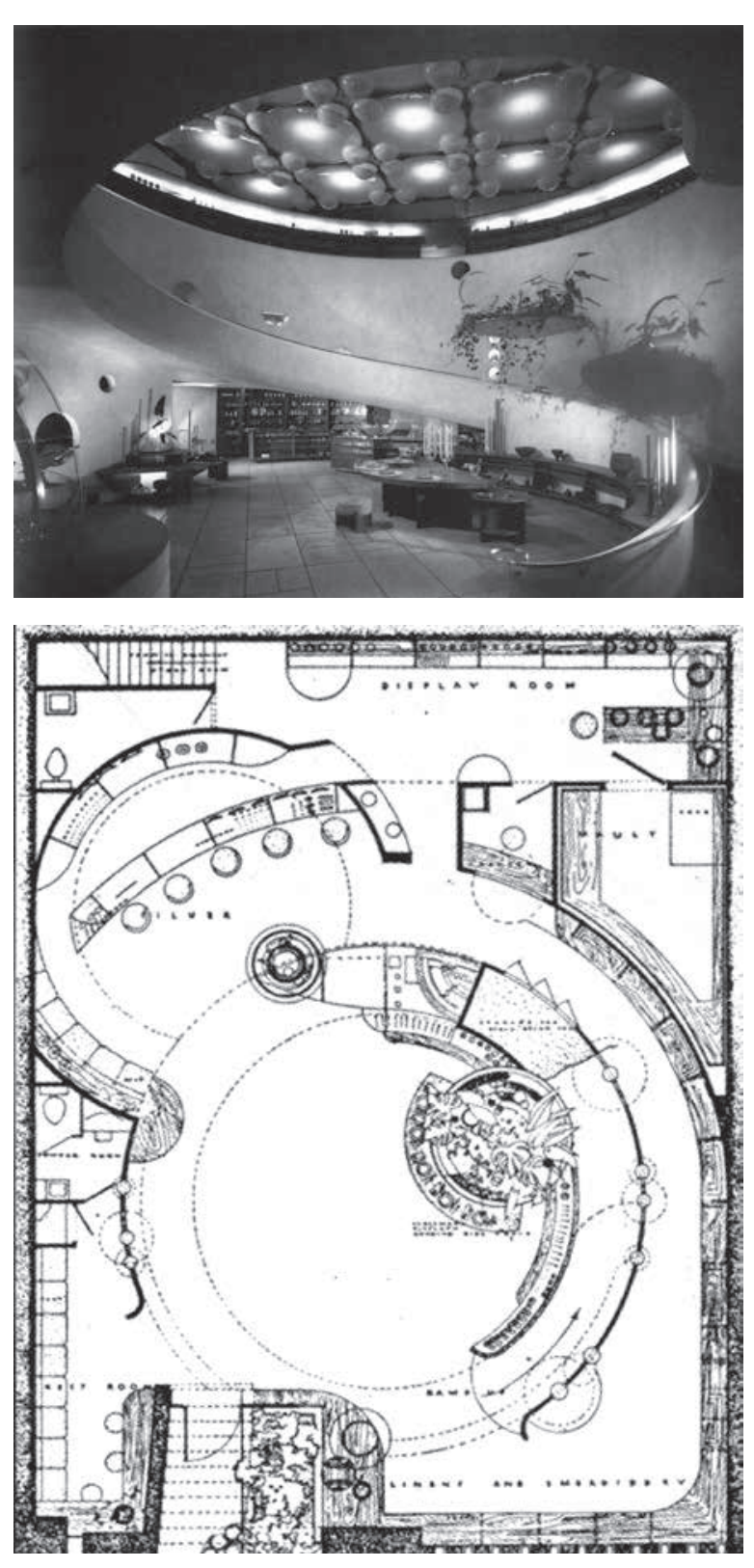

espiral invertida que progresivamente aumenta su radio de curvatura en el exterior del edificio mientras que, en e Interior, la rampa que delimita el gran patio central circular va disminuyendo de radio y, en vez de expandirse, se va reduciendo (igura 11). La voluntad expresiva de conseguir un sistema compositivo absolutamente continuo tanto en el exterior como en el interior se acentúa todavia más gracias a la ausencia de relieve de los paramentos giratorios, construlidos en hormigón sin despieces que los interumpan. Las lineas de sombra que acompañan el recorrido de las paredes y la corporeidad y plasticiacentúan todavia más este efecto de despliegue infinito.
9. Frank LLoyd Wright, Morris Girt Shop. San 10. Frank Loyd Wright, Museo Guggenh im. Nueva York, 1956- 59. Planta baja. 11. Frank LLoyd Wright, Museo Guggennheim.
Nueva York, 1956- 59. Sección y vista ex terior.

12. Frank Lloyd Wright, Museo Guggenhe im. Nueva Von, 1956- 59. Espacio cent

De manera parecida al edificio de San Francisco, en el nterior del Guggenheim, el arte, la vida y el movimiento conviven en un mundo onírico y excepcional. Después de cruzar el porche de acceso, el visitante alcanza, mediante unos ascensores, la parte más elevada del museo, amparada por la gran linterna en forma de casquete esférico que cubre el espacio central y que actúa de límite final de trazado espiral (figura 12). A partir de esta atalaya privilegiada desde donde reconocer la magnitud del artefacto, comienza un trayecto descendente a lo largo de unos 400 metros, que permite pasear entre las obras de arte expuestas tanto en los planos verticales radiales como en las paredes perimetrales. Éstas, ligeramente inclinadas, gozan de la iluminación indirecla que proviene de las llagas exteriores. Al mismo tiempo, en es pre ceremonia descenso, uno puede disfrutar de la visión simultanea de todo el interior, contemplar el gran patio central y ser, a la vez, testimonio del movimiento del resto de visitantes que se encuentran en otras partes del edificio.

En su configuración externa, el museo Guggenheim se presenta como ungran organismo sin fisuras que, con voluntad autista a nivel espacial, programático y urbano, se encierra en si mismo. Como si se tratara de una nave extraterrestre, se coloca en medio de la reticula urbana de Nueva York, indiferente a la cartesiana trama que lo rodea (figura 11). En este sentido, el cerramiento hermético y el crecimiento en espiral del edificio de Wright, contiene las mismas reglas generatrices que algunos de los organismos animales descritos por Cook y Thomson en sus textos (figuras 3 y 12)

PROYECTOS DE DESARROLLO ESPIRAL EN ESPAÑA Durante la década en que Wright empieza a desplegar sus proyectos en desarrollo espiral parecidos a los ziggurats babilonicos, el arquitecto madrileño Casto Fernández Shaw utiliza esta misma geometria para la resolución de una serie de edificios singulares. Los más premonitorio son el faro-monumento a la memoria de Colón en la lsla de Santo Domingo, y el faro-torre de control del aeropuerIo de Barajas, ambos de 1929. Más adelante, en 1949 realiza la maqueta y los dirbujos de una torre helicoida similar a la collumna trajana para el faro de la hispanidad los proyectos de Tatlin, Kiesler o Wright no invalidan la

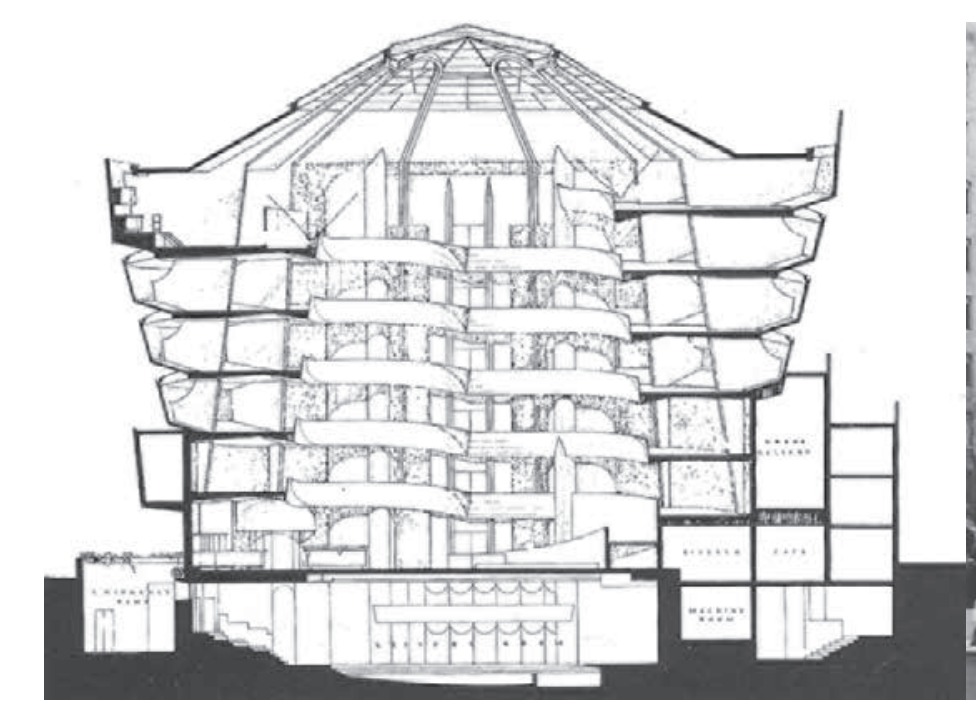

10
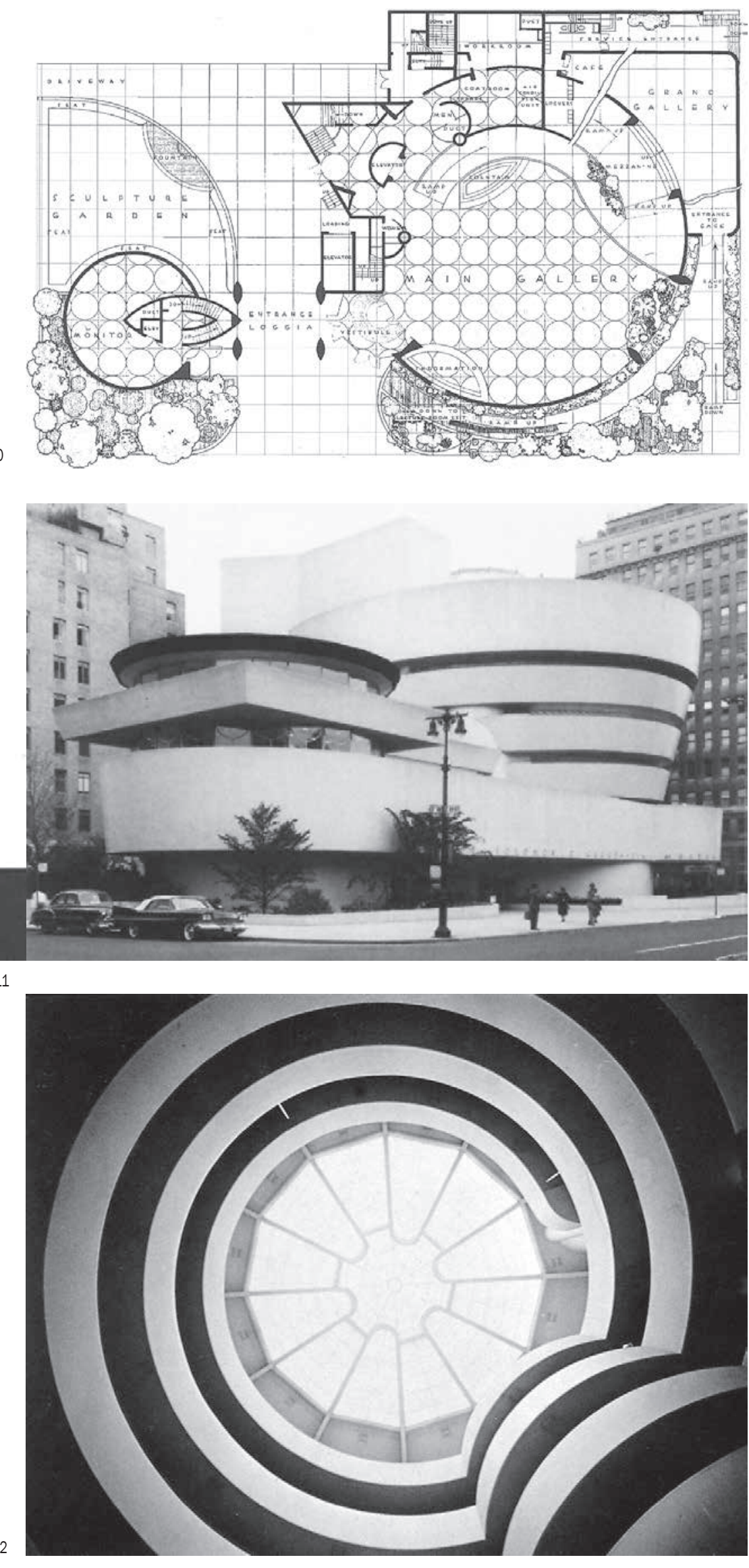

M. MÀRA. "Arquitecturas sin fin". N8. Mayo 2013. Universidad de Sevilla. ISSN 2171-6897/ / SSNN 2173-1616 

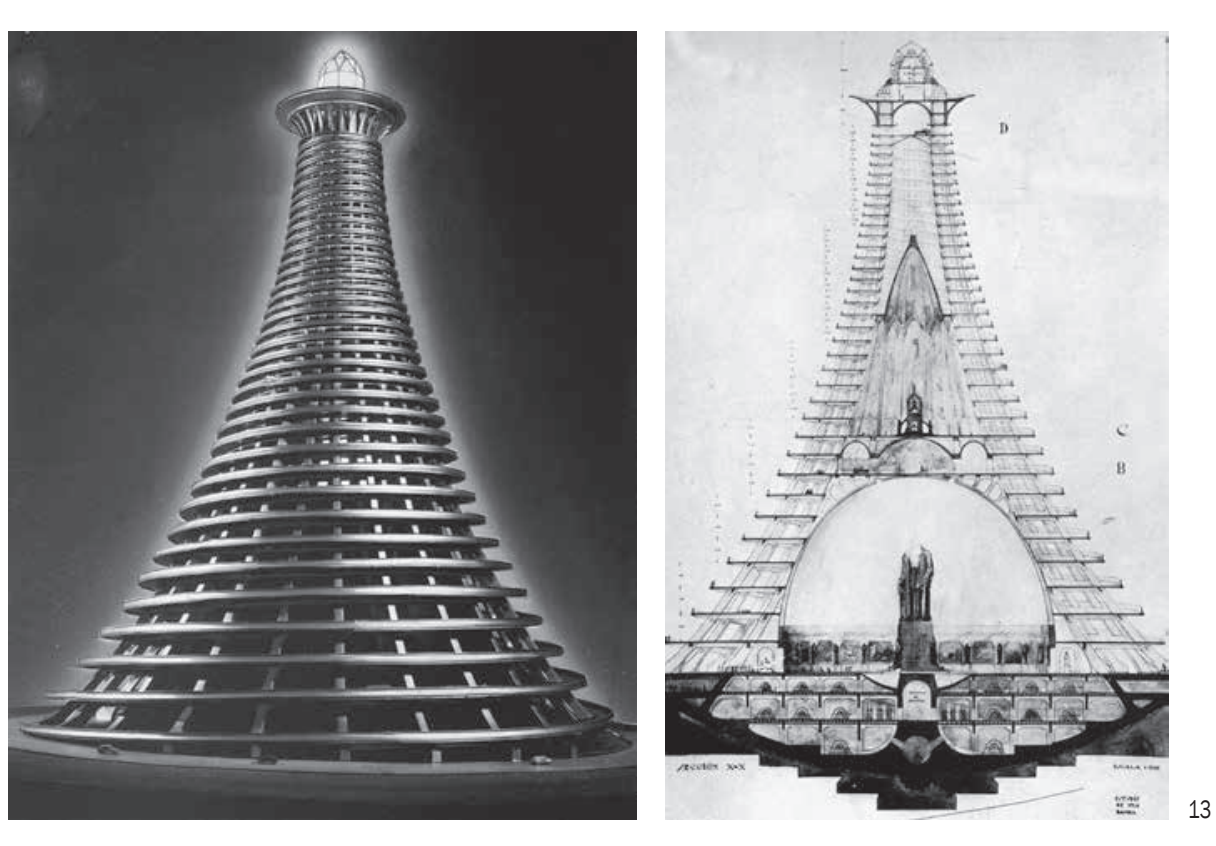

13. Casto Fernández Shaw, Faro Monu1929. Maqueta y sección.

14. Francisco Javier Sáenz de Oíza. Edificio tas 22 y 23 .

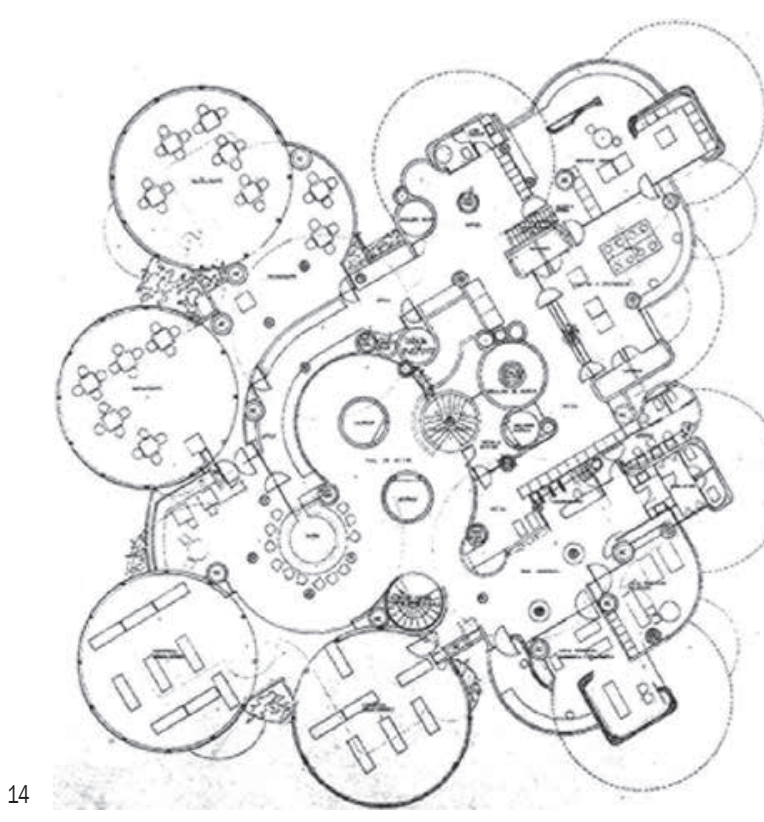

de distintas formas y tamaños que confluyen en el gran escenario central. Dentro de esta línea son destacables también las propuestas de Rafael Aburto, Femandez Longoria, Rafael Moneo o Daniel Fullaondo.

Pero, a la vez, todos estos diseños orgánicos se encuentran vinculados con algunos de los trabajos que en 1961 está elaborando Francisco Javier Sáenz de Oiza en Madrid, como la maqueta para las escuelas de Batán, 0 los dibujos del centro social de Torres Blancas, situado en las plantas 22 y 23 del rascacielos (figura 14). De hecho, tanto Moneo como Fullaondo colaboran con el maestro madrileño en el diseño de este simbólico conjunto de viviendas y oficinas, poco antes de participar en el concurso de la Operay Palacio de Congresos de Madrid. Será mismo Daniel Fullaondo quien, a partir de 1967, a través de la revista Nueva Forma, se ocupará de difundir tanto el proceso de elaboración del edificio de Torres Blancas, como otras obras y proyectos de arquitectos que trabajan con estas singulares geometrias de expansión logaritmica. el mismo Frank Lloyd Wright, Casto Fennández Shaw 0 algunos de sus companeros arquitectos participantes Sánz de Oiza un apa de Madid.

Sanzí con matemáticas y la geometra, contra un armbucion de las viviendas y oficinas América aun esquema en esúricasimila al de Avs

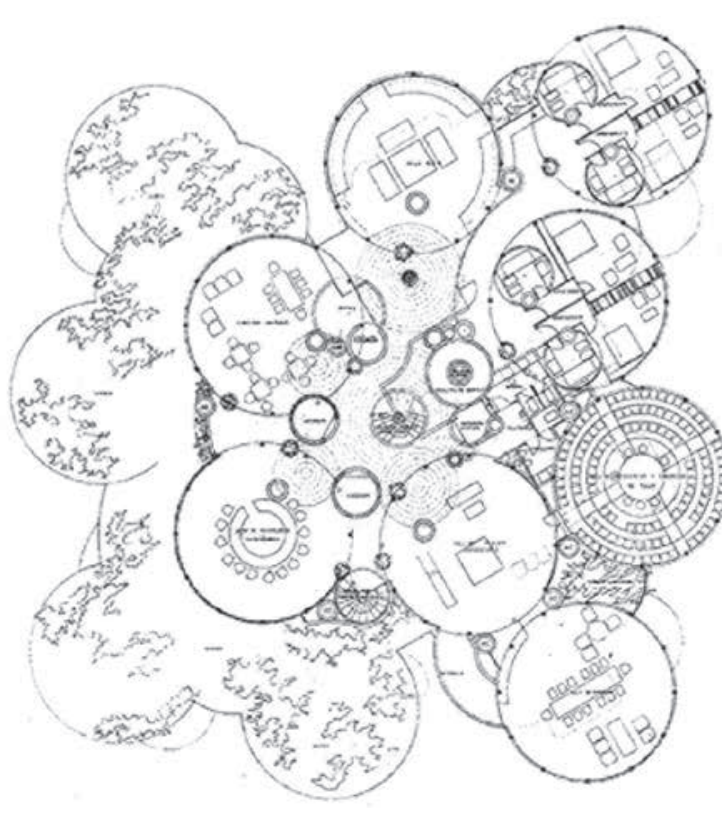

St. Mark (1925-29) y Price de Wright (1952-56), suster tado por una estructura arbórea compuesta de cilindros de hormigon autoportantes que nacen del subsuelo y que adoptan multiples funciones. escaleras, ascensores, lava-

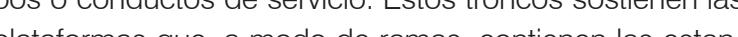
cin y as teraz, as permitiendo, as a vezl lib las estande conjunto2. Pero a diferencia de estos sing el centro cacies del mactro a dicrecia de estón singulares rasestructura arbórea cada vez más liviana que desdibuja

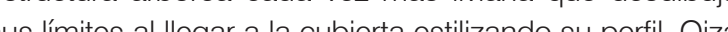
decide colmar Torres Blancas de mane su pent, Olza con un coniunto de praformas circula con a as viviendas inferiores, de manera parecida a los pileos de unos hongos 0 a las órbitas de unos platilos volanes flotando sobre el cielo de Madrid. Esta solución dedibuja en planta la matriz en essástica que organiza las cutro viviendas por relliano de la mayor parte del edificio Los círulbs de tamaños distintos que contienen ror palas comultais los comercios o el gimnasio-, se expanden de manera centrípeta dejando el centro vací y proporcionando a la planta 23 el espacio intersticial en Plura necesario para albergar el vaso de la piscinásta se sitúa en la cubierta y va resiguiendo los contornos

la Exposición del Ministerio de Fomento, 1999, pp. 63-67 y 96.

17. Para entender la influencia de Wright sobre esta seneración de arouitectos es imprescindible el siguiente articulo: Sánchez Lampreave Ricardo: "Línites

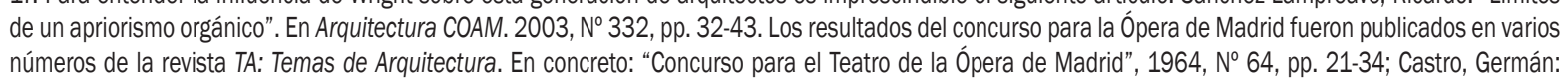

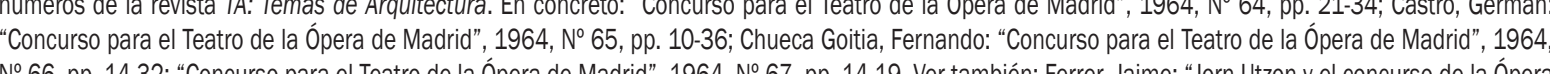

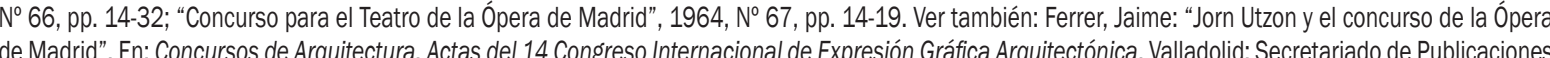
e Intercambio Editorial, 2012, pp. 403-409.

18. Entre estos proyectos destacan las diez residencias para artistas de Monte EI Pardo en Madrid (1960), el Centro de Restauraciones de Madrid, en el que colabora Rafael Moneo (1961), la casa Wutrich en Lanzarorte (1962) o el Pabellón españonl para la Feria Internacional de Nueva York (1963). Ver los números monográáicicos dedicados a estos arquitectos en la revista Nueva Forma. Noviembre-Diciembre 1969, № 46-47; Febrero 1970, № 49; Junio 1971 , № 65.

19. Sobre el proyecto de Torres Blancas ver: Nueva Forma. Febrero 1967, № 13; Marzo 1967, № 14; Abril 1967, № 15; Mayo 1967, № 16. Sobre Casto Fer

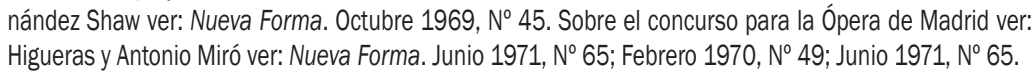
20. Capitel, Antón: "Las ideas orgánicicas como instrumentos de proyecto. Torres Blancas y otras obras de Sáenz de Oíza". En Anales de arquitectura. 1990, N 
15. Ignacio Avarez Castelao, Facultad Cien cias Biolósicas y Geolós
Planta yvista interior. 16. Rafael de la Hoz, Palacio de Congresos.
Torremolinos, 1965- 1967. Planta y vista interior.
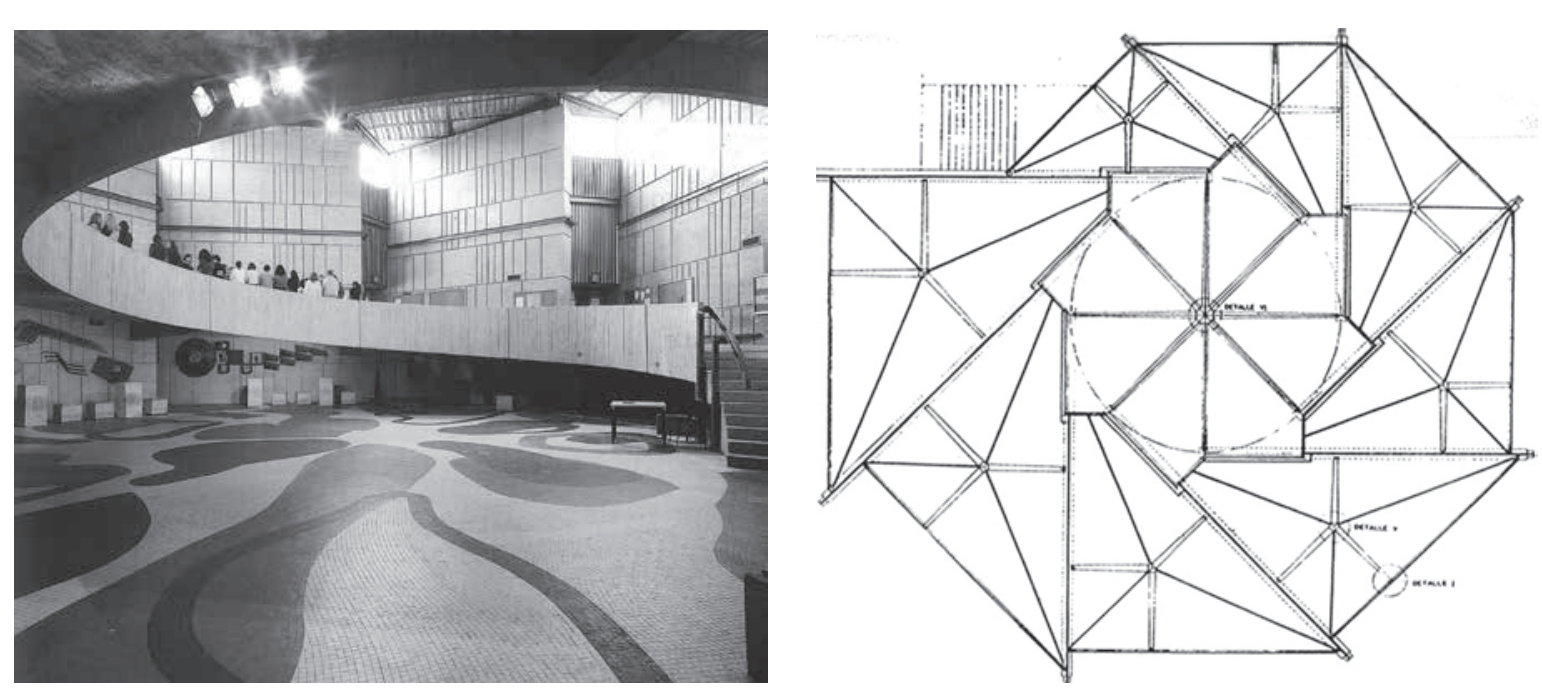
circulares centrales, sorteando las imponentes chime-
neas y adoptando una forma de ameba que convive con las tuberías y la vegetación del jardín superior.

Esta concatenación de círculos enlaza íntimamente con la familia de proyectos de Wright y con las bases geométricas de los esquemas de crecimiento logarítmico trazados por Cook (figuras 4 y 14). También resulta muy próxima a la unicidad orgánica y material de Wright la resolución de los interiores de los espacios comunes de la torre, tanto del núcleo central como del centro social de las últimas plantas. Las volumetrías futuristas, las esferas cristalinas, las ventanas redondeadas, el mobiliario circular adaptado al perímetro y el conjunto de objetos naturales y artificiales de formas bulbosas y antropomórficas, conservan las reminiscencias del mundo onírico wrightiano, a caballo entre la organicidad submarina y la estética futurista. estructurales y expresivas del material constructivo, el hormigón, y su identidad con el resultado formal del conjunto Y también con el carácter eminentemente singular y la voluntad de separación expresiva del rascacielos respecto a entorno inmediato que, según confiesa el propio Sáenz de Oiza, es parecida a la actitud del Guggenheim respecto a los edificios de la $5^{a}$ avenida de Nueva York' ${ }^{21}$. El rascacielos

de Madrid, como muchos de estos proyectos de matriz logaritmica, nace mucho antes que la elección del en clave, pudiendo estar ubicado en cualquier otro lugar. Otro de los edificios que durante estos años aplica iteralmente el esquema de Cook basado en el desarroo logarítmico de una espiral rodeada de unidades que aumentan progresivamente de tamaño es el aulario de la Facultad de Ciencias Biológicas y Geológicas de Oviedo. Este edificio, también autónomo respecto al entorno, coexiste con un bloque laminar paralelepípedo de más altura en el que se ubican los departamentos de la Facultad El conjunto es construido en 1965 por el ingeniero y arquiecto asturiano Ignacio Alvarez Castelao, un profesional muy aficionado a las matemáticas y con una extraordinaria vocación investigadora ${ }^{22}$. Situado en una manzana aislada de un céntrico polígono industrial, la libertad de los contornos exteriores de la parcela permite al arquitecto expandir en planta y en altura ocho aulas en forma de trángulos rectangulos decrecientes dispuestos alrededor de un vestibulo central de planta circular. Los triángulos unen su hipolenusa al cateto del siguiente $y$, como en e pexsivo, sus partes se encuentran relacionadas proporcionalmente por la sección áurea (figura 15).

21. Entrevista con Javier Saenz de Oíza. Revista El Croquis. 1988, N $32-33$, pp. 27-28. Ver también: Longoria, Francisco: "Contradicción y contrapunto en las

20rres Blancas". En Arquitectura COAM. Diciembre 1968, No 120, pp. 3-30.
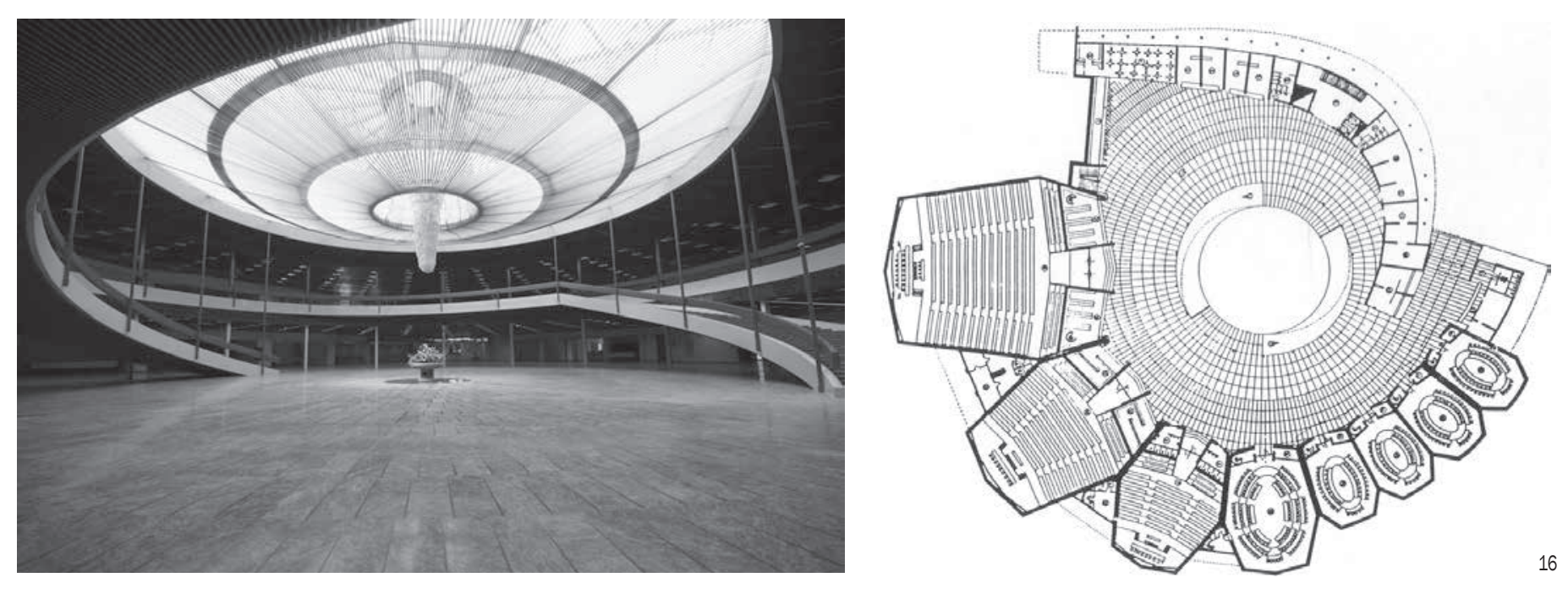

A las distintas aulas se accede gracias a un tramo de escalera y al recorrido paulatino de una rampa helicoida que resigue perimetralmente el cilíndrico vacío central. Este elemento, con una vocación eminentemente congregadora, se resuelve de manera similar a la casa de David Wright en Phoenix o a la Morris Gift Shop (figuras 8 y 9). recorrido vinculado al vacío acentúa todavía más la cualidad espacio-temporal de todo el proyecto, permite el acceso a los distintos niveles del conjunto, y contribuye a caracterizar el sugestivo espacio central de "aspecto cavernario"23 que, además de realizar las funciones de gran vestibulo y distribuidor, vertebra a su alrededor todas las piezas del edificio. En este hall, la aspereza de hormigón que resuelve la continuidad de la barandilla y los ocho muros tangentes que dan paso a las aulas, unida a la austeridad de la estructura metálica estrellada de la cubierta, contrasta con la sinuosidad y organicidad de mosaico de amebas disenado por Antonio Suárez que recorre el suelo. El espacio resultante, subrayado por la ausencia de vistas directas del exterior y por la misteriosa iluminación que penetra de manera tangencial, recrea nuevamente un ambiente onirico y submarino (igura 15). Las aulas triangulares también se resuelven con cubierlas metálicas en pendiente, configurando un sugestivo conjunto de piezas desplegadas que puede ser contemplado

desde la mayor altura del edificio de los departamentos. Al mantener la misma cota en la cubierta el suelo inclinado de las aulas y su diferente tamaño hacen que sus alturas vayan cambiando progresivamente. Bajo sus foriados van quedando espacios en los que se sitúan las entradas y otros locales de servicio, adaptandose a los desniveles del terreno. Durante el mismo año 1965 Rafael de la Hoz y Gerardo Olivares proyectan el Centro de Congresos de Torremolinos. Inaugurado en 1967, su organización responde a una composición similar a la del Aulario de la Facultad de Geológicas de Oviedo. Un gran vestíbulo circular central resuelto a dos niveles vertebra todas las piezas que se reparten de manera centrípeta. Dos escaleras leonardescas que se desarrollan marcando el límite del espacio circular, conducen al nivel superior, desde el que se accede a las salas de congresos.

Estos volúmenes, de geometría poligonal similar, van aumentando su tamaño de manera logaritmica. Como en los procesos naturales, sus formas son clonnicas pero diferen entre ellas en magnitud y cantidad de materia, que aumentan a medida que se alejan del origen (igura 16 . (a) - exterior, como las aulas de Oviedo, conservan su singularidad, manifestandose en voladizo respecto a la estructura central. El amplio vestibulo interior 23. Arancón, Geraraddo "Facultad de Ciencias Biológicas y Geelógicas". En García, Celestino; Agrasar, Fernando: Arruitectura moderna en Asturias, Galicicia, 
queda cerrado con una lámpara-lucernario que evoca el gran poder ornamental de las arañas de cristal de antaño. Su diseño helicoidal ascendente, combinado con una estructura radial en la cubierta que sostiene la doble piel de vidrio, es similar al gran lucernario que cubre el Museo Guggenheim de Nueva York, impidiendo la visión abierta del cielo y contribuyendo a escenificar una ambientación envolvente y misteriosa (figura 16).

El carácter eminentemente cerrado de los exteriores, similar al de unas conchas incrustadas sobre un cuerpo cenfral imperceptible, se acentúa con el aplacado de piedra de os paramentos. La privilegiada situación del conjunto, en batto de una colina, contribuye a convertirio en un artefacto autônomo, similar a un gran organismo de orden natural24 De manera parecida al proyecto de Alvarez Castelao, el resto de programa del edificio se concentra en una crulia curva y alargada situada también alrededor del patio circular central. Este cuerpo fusilorme, a diferencia de las salas de congresos, es tratado de manera más abierta y acristalada.
En todos estos proyectos, las trazas geométricas formas atomizadas que, de manera homogénea o heteogénea, se expanden por el plano o por el espacio alrededor de un centro. Muchas de las formas derivadas de estas matrices de crecimiento y extensión, semejantes a os procesos naturales, demuestran infinitas posibilidades de combinatoria al manifestarse como generadoras logica no está reñida con su capacidad de moldeabilidad y adaptabilidad a cualquier proceso constructivo, programa o emplazamiento. En este sentido, las propuestas experimentales de Emberton, Wright o los organicistas españoles de mediados del siglo XX que siguen la estela de los ejemplos presentes en la natualezay nen las ate sistematizados por Sir Theodore Cook y D Arcy Thomson ofrecen un amplio abanico de posibilicades que permiten seguir explorando estos procesos de crecimiento desde el proyecto arquitectónico. ermiten controlar a través de su desarrollo logarítmico de un proceso abierto. Así, su aparente autonomía morfo-

\section{Bibliografí}

A.W: The Solomon R. Guggenheim Museum. Nueva York: Guggenhheim Museum Publications, 1995.

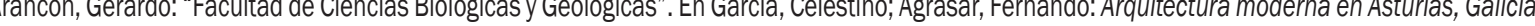
Castilla y León. ortodoxia, márgenes y transogresiones. COA Asturias; COA Galicia; COA Castilla y León Este; COA León, 1998.

Bachelard, Gaston: La poetica del espaciio. Madrid: Fondo de Cutura Económica, 1965.

Bogner, Dieter: Friedrich Kiesler. Architekt Maler Bildhauer 1890-1965. Wien: Löcker Verlag, 1988.

Brooks Pfeiffer, Bruce: Frank Lloyd Wright. Monoograph. Tokio: ADA, 1985.

Cabrero, Félix: Casto Fernández-Shaw. Madrid: COAM, 1980.

Capitel, Anton: "Las ideas orgánicas como instrumentos de proyecto. Torres Blancas y otras obras de Sáenz de Oíza". En Anales de arquitectura. $1990, N^{\circ} 2$.

Casto Fernández-Shaw. Arquitecto sin fronteras, 1896-1978. Madrid: Catálogo de la Exposición del Ministerio de Fomento, 1999.

Castro, Germán: "Concurso para el Teatro de la Ópera de Madrid". En Temas de Arquitectura. 1964, № 65.

Colman, Samuel; Coan, Clarence Arthur: Nature's Harmonic Unity. A treatise on its relation to proportional form. G.P. Putnam's Sons, 1912.

Cook, Theodore: The Curves of Life. London: Constable and Company, 1914. New York: Dover Publication, 1979.

Charbonneaux-Lassay Louis: Le Bestiaire du Christ La mystérieuse emblématique de lésus-Christ. Bruges:- Desclée de Brouwer, 1940.

Chueca Goitia, Fernando: "Concurso para el Teatro de la Ópera de Madrid". En Temas de Arquitectura. 1964, № 66.

24. “Enclavado en una colina (.... el elificio se expressa como una espirial monumental que parecierara no apoyar en el suelo". Ver. Peña, Antonio; Díaz, Jose, Daroca, Francisco (ed.): Rafael de la Hoz. Arquitecto. Catálogo de Obras y Proyectos. Córdoba: Demarcación de Córdoba del Colegio Oficial de Arquitectos de
Andalucía occidental, 1991, pp. 113.
Dezzi Bardeschi, Marco: Frank Lloyd Wright. Firenze: Sansoni ed., 1977. Drexler, Arthur: The drawings of Frank Lloyd Wright. New York: Horizon Press, 1962. El Croquis. 1988, № 32-33.

errer, Jaime: "Jom Utzon y el concurso de la Opera de Madrid" En Concursos de Arquitectura. Actas del 14 Congreso Internacional de Expresión Gráfica Arquitectónica. Valladolid: Secretariado de Publicaciones e Intercambio Editorial, 2012.

García-Pola, Miguel Angel, "Astưries. L'èpica del desenvolupament”. En Quaderns d'Arquitectura i Urbanisme. 1997, № 215. Gallimard, 1927 .

Ghika, Mathila: Le Nombre d'or /El número de oro. Paris: Gallimard, 1931

Hambidge, Jay: Dynamic Symmetry: The Greek Vase. Yale University Press, 1920

Hoffman, J.E." “Bernoulli, Jakobl”. En Dictionary of Scientific Biography, 2. New York: Charles Scribner's Sons, $1970-80$ (PMid:20883532 PMCid:2956128 Ind, Rosemary: Emberton. London: Scolar Press, 1983

Izzo, Alberto; Gubitosi, Camillo: Frank Lloyd Wright. Drawings 1887-1959. Firenze: Centro Di Stiav, 1977.

Levine, Neil: The architecture of Frank Lloyd Wright. New Jersey: Princeton University Press 1996.

odder, Christina: Russian Constructivism. New Haven: Vale University Press, 1983. El constructivismo ruso Madrid: Alianza editorial 1988.

Lloyd Wright, Frank: An American Architecture. New York: Edgar Kaufmann, 1955.

Longoria, Francisco: "Contradicción y contrapunto en las Torres Blancas". Arquitectura COAM, nº 120, Diciembre 1968.

Nueva Forma. Febrero 1967, № 13; Marzo 1967, № 14; Abril 1967, № 15; Mayo 1967, № 16; Octubre 1969, № 45; Noviembre-Diciembre 1969, N

.

Pedretti, Carlo: Leonardo architetto. Milano: Electa, 1978.

Peña, Antonio; Día, José; Daroca, Francisco (ed.): Rafael de la Hoz. Arquitecto. Catálogo de Obras y Proyectos. Córdoba: Demarcación de Córdoba de

Quaderns d'arquitectura i urbanisme. 1999, № 222

Sánchez Lampreave, Ricardo: “Límites de un apriorismo orgánico". En Arquitectura COAM. 2003, № 332.

Starr, Frederick: Melnikov. New Jersey: Solo Architect in Mass Society. Princeton University Press, 1981.

Storrer, William Allin: The Frank Lloyd Wright Companion. Chicago: The University of Chicago Press, 1993.

Temas de Arquitectura n` 65 y 67,1964

The Guggenheim. Frank Lloyd Wright and the making of the Modern Museum. New York: Solomon R. Guggenheim Foundation, 2009.

Thomson, D'Arcy: On Growth and Form. Cambridge: The Presss Syndicate of the University of Cambridge, 1917. Sobre el crecimiento y la forma.

Von Moos, Stanislaus: Le Corbusier. Barcelona: Ed. Lumen, 1977.

Magda Mària i Serrano. Arquitecta ETSAV UPC, 1987. Doctora Arquitecta UPC, 1995. Profesora Agregada Proyectos Arquitectónicos. Departamento Proyectos Arquitectónicos. UPC. Responsable del Taller de Arquitectura y Proyectos G. ETSA Vallès, 2006-ac tualidad. Profeseora de Máster de Teoría y Práctica del Proyecto. ETSA Barcelona UPC. Co-responsable del Grupo de Investigación HABITAR: www.habitar.upc.edu. Comisariado, diseño y redacción de catálogos del ciclo de exposiciones REHABITAR. Madrid, Sala La Arquería de Nuevos Ministerios, 2010-2012. Subdirectora de Plan de Estudios ETSAV, 2008-2011. Ha publicado artículos en las revistas: Tectónica, att, PPA, ACE, Locus Aomenus, Goya. Autora o coautora de los libros: Renaixement i arquitectura religiosa, 2001; Forma-Pensamiento: interacciones entre pensamiento arquitectónico y filisófico, 2005; Rehabitar en 9 episodios, 2012. Arquitecta socia de metamortosi arquitectes slp. Coautora del plan estratégico y rehabilitación del Palacio Episcopal de Barcelo
comisariado, diseño y contenidos de la Colección de Carrozas Funnebres de Cementerios de Barcelona, 2011-2013. 


\section{Autor imagen y fuente bibliográfica de procedencia}

Información facilitada por los autores de los artículos: página 29, 1 (Canogar, Daniel: Ciudades efímeras. Exposiciones Universales: Espectáculo y Tecnología. Madrid: Julio Otero, 1992); página 30, 2 (Der Baumeister, vol. 29, № 7. Julio 1931. München: Verlag Georg D.W. Callwey); página 32, 3 y 4 (McQuaid, Matilda: Lilly Reich. Designer and Architect. New York: Museum of Modern Art, New York. Distributed by Harry N. Abrams, INC., 1996), 5 y 6 (Von Ursel, H. \& Pavel, T: Barcelona Pavilion. Mies van der Rohe \& Kolbe. Architecture \& Sculpture. Berlin: Jovis Verlag, 2006), página 34, 7 (The Mies van der Rohe Archive. Part I, 1910-1937. Vol. 1. New York: Garland, 1986), 8 (Revista 2G. "Mies van der Rohe. Casas". No 48-49. Barcelona: Gustavo Gili, 2009); página 35, 9 (The Mies van der Rohe Archive. Part I, 1910-1937. Vol. 1. New York: Garland, 198), 10 y 11 (McQuaid, Matilda: Lilly Reich. Designer and Architect. New York: Museum of Modern Art, New York. Distribued by Harry N. Abrams, INC., 1996); página 36, 12 (Departamento de Arquitectura del The Museum of Modern Art, The Mies van der Rohe Archive, New York), 13 y 14 (Der Baumeister, vol. 29, № 7. Julio 1931. München: Verlag Georg D.W. Callwey); página 37, 15 (Derecha; AAVV: Mies in Berlin. New York: Museum of Modern Art. Distributed by Harry N. Abrams, INC., 2001. Izquierda; McQuaid, Matilda: Lilly Reich. Designer and Architect. New York: Museum of Modern Art, New York. Distributed by Harry N. Abrams, INC., 1996); página 44, 1 y 2 (AA. W.: Mies in Berlin. New York / Berlín: MoMA, 2001, p. 175, figura 36 y p. p. 169. figura. 25); página 45, 3 y 4 (Schulze, Franz (ed); Darforth, George E. (ed. consulting): The Mies van der Rohe Archive". New York: Garland, 1986-1992, volumen 1, p. 86 y volumen 1, p. 91); página 46, 5 y 6 (Schulze, Franz (ed); Darforth, George E. (ed. consulting): The Mies van der Rohe Archive". New York: Garland, 19861992, volume 1, p. 288 y volume 1, p. 183); página 46, 7 (AA. W.: Mies in Berlin. New York / Berlín: MoMA, 2001, p. 97); página 48, 8 a 10 (Schulze, Franz (ed); Darforth, George E. (ed. consulting): The Mies van der Rohe Archive". New York: Garland, 1986-1992, volumen 20, p. 300 y p.122); página 48, 11 a 13 (Schulze, Franz (ed); Darforth, George E. (ed. consulting): The Mies van der Rohe Archive". Nwe York: Garland, 1986-1992, volumen 4, p. 390, p. 415 y p. 393); página 50, 14 y 15 (Schulze, Franz (ed); Darforth, George E. (ed. consulting): The Mies van der Rohe Archive". Nwe York: Garland, 1986-1992, volumen 4, p. 389 y p. 75); página 56, 16 (Schulze, Franz (ed); Darforth, George E. (ed. consulting): The Mies van der Rohe Archive". Nwe York: Garland, 1986-1992, volumen 4, p. 78); página 59, 1 (Bloc, André: De la sculpture a l'architecture. Boulogne (Seine): Editions Aujourd'hui, 1964. p. 100) ; página 61, 2 (Bloc, André: De la sculpture a l'architecture. Boulogne (Seine): Editions Aujourd'hui, 1964. p. 101), 3 (Amon, Santiago:"La exaltación del orden artificial en la arquitectura de Parent y Bloc". En Nueva Forma. Marzo de 1967, № 50. p. 4); página 62, 4, 5 y 6 (Bloc, André: De la sculpture a l'architecture. Boulogne (Seine): Editions Aujourd'hui, 1964. p. 96, p. 93 y p. 95 ); página 64, 7, 8 y 9 (Bloc, André: De la sculpture a l'architecture. Boulogne (Seine): Editions Aujourd'hui, 1964. p. 97 y p. 100); página 68, 10 (Migayrou, Frédéric: Bloc Le Monolithe Fracturé. Orléans: Éditions HYX, 1996. p. 30), 11 (Héctor GarcíaDiego Villarías, María Villanueva Fernández), página 70, 12 (Héctor García-Diego Villarías, María Villanueva Fernández); página 74, 1 (Lipman, Jonathan: Frank Lloyd Wright and the Johnson Wax Buildingss. New York: Dover Publications, 2003. Republicación de la edición original de Rizzoli, 1986. p. 60); página 75, 2 (Signatura 12-154 OCSIC, Instituto de Ciencias de la Construcción Eduardo Torroja (IETcC)), 3 (Architectural Forum. Vol.102. No5. Mayo 1955. p. 86); página 76, 4 (Signatura DIBZ-058 Fondo Zuazo. Biblioteca Nacional de España), 5 (Víctor Larripa Artieda); página 78, 6 y 7 (Víctor Larripa Artieda); página 80, 8 y 9 (Signatura DIBZ-058 Fondo Zuazo. Biblioteca Nacional de España); página 82, 10 (Cahiers d’art. 4ème année. No6. 1929. p. 278), 11 (Signatura 11-8 @CSIC, Instituto de Ciencias de la Construcción Eduardo Torroja (IETcC)); página 84, 12 (Arquitectura. № 10. 0ctubre 1959. Madrid: COAM. p. 7); página 85, 13 (Signatura DIBZ-058 Fondo Zuazo. Biblioteca Nacional de España), 14 (Víctor Larripa Artieda); página 86, 15 (Signatura 007F.RET @CSIC, Instituto de Ciencias de la Construcción Eduardo Torroja (IETcc)); página 90, 1 (Thomson, D’Arcy: Sobre el crecimiento y la forma. Madrid: Cambridge University Press, 2003); página 91, 2 y 3 (Cook, Theodore: The Curves of Life. London: Dover Publication, 1979); página 92, 4 (Cook, Theodore: The Curves of Life. London: Dover Publication, 1979), 5 (Ind, Rosemary: Emberton. London: Scolar Press, 1983 ); página 93, 6 (Drexler, Arthur: The drawings of Frank Lloyd Wright. New York: Horizon Press, 19); página 94, 7 (Brooks Pfeiffer, Bruce: Frank Lloyd Wright. Monograph. Tokio: ADA, 1985), 8 (Izzo, Alberto, Gubitosi, Camillo: Frank Lloyd Wright. Drawingss 1887-1959. Firenze: Centro Di Stiav, 1977); página 96, 9 (Levine, Neil: The architecture of Frank Lloyd Wright. New Jersey: Princeton University Press, 1996. Rasmussen, Steen Eiler, Experiencia de la arquitectura. Barcelona: Ed. Labor, 1974); página 97, 10 y 11 (AA.W: The Solomon R. Guggenheim Museum. Nueva York: Guggenheim Museum Publications, 1995$), 12$ (Levine, Neil: The architecture of Frank Lloyd Wright. New Jersey: Princeton University Press, 1996); página 98, 13 (Casto Fernández-Shaw. Arquitecto sin fronteras, 1896-1978. Madrid: Catálogo de la Exposición del Ministerio de Fomento, 1999; Cabrero, Félix: Casto Fernández-Shaw. Madrid: COAM, 1980); página 99, 14 (El Croquis. 1988, № 32-33); página 100, 15 (García-Pola, Miguel Ángel, “Astúries. L'ènica del desenvolupament”. En Quaderns d'Arquitectura i Urbanisme. 1997, № 215; García, Celestino; Agrasar, Fernando: Arquitectura moderna en Asturias, Galicia, Castilla y León. Ortodoxia, márgenes y transǵresiones. COA Asturias; COA Galicia; COA Castilla y León Este; COA León, 1998); página 101, 16 (Peña, Antonio; Díaz, José; Daroca, Francisco (ed.): Rafael de La-Hoz. Arquitecto. Catálogo de obras y proyectos. Córdoba: Demarcación de Córdoba del Colegio de Arquitectos de Andalucía Oriental, 1991); página 105, 1 (Collection George E. Thomas); página 107, 2 (Tribune Company); página 108, 3 (Scott Gilchrist, Archivision Inc.), 4 y 5 (The Frank Lloyd Wright Foundation Archives (The Museum of Modern Art \& Avery Architectural \& Fine Arts Library, Columbia University, New York); página 110, 6 (The Frank Lloyd Wright Foundation Archives (The Museum of Modern Art \& Avery Architectural \& Fine Arts Library, Columbia University, New York)); página 111, 7 (Alfonso Díaz Montes), 8 (Collection Alden Franz Aust); páginas 112 a 114, 9 a 14 (The Frank Lloyd Wright Foundation Archives (The Museum of Modern Art \& Avery Architectural \& Fine Arts Library, Columbia University, New York)); página 115, 15 (Wisconsin Historical Society); página 120, 1 (Rodchenko-Stepanova. Todo es un experimento (catálogo homónimo de la exposición). Madrid: Fundación Banco Central Hispanoamericano, 1992); página 121, 2 (Chan-Magomedov, Selim Omarovich: NikolajLadovskij. Un'ideologia del razionalismo. Lotus International nº 20, septiembre 1978. Milán: Electa), 3 (Nerdinger, Winfried: Walter Gropius. Opera completa. Milán: Electa, 1985; y Giedion, Sigfried: Walter Gropius. L'homme et l'oeuvre. París: Albert Morancé, 1954); página 122, 4 (Ciucci, Giorgio; De Michelis, Marco (Eds.): Giuseppe Terragni (catálogo homónimo de la exposición). Madrid: Ministerio de Fomento-Junta de Andalucía, 1996; y Vitrum n 134, noviembre-diciembre 1962. Milán: s.e.), 5 (Joedicke, Jürgen (Ed.): La comunidad de arquitectos Van den Broek/Bakema. Barcelona: Gustavo Gili, 1978); página 123, 6 (Archivo Corrales); página 125, 7 (Sánchez Lampreave, Ricardo (Ed.): Miguel Fisac. Premio Nacional de Arquitectura 2002. Madrid: Ministerio de Vivienda, 2009), 8 (Arques Soler, Francisco: Miguel Fisac. Madrid: Pronaos, 1996); página 127, 9 y 10 (Sánchez Lampreave, Ricardo (Ed.): Miguel Fisac. Premio Nacional de Arquitectura 2002. Madrid: Ministerio de Vivienda, 2009); página 128, 11 (Sánchez Lampreave, Ricardo. Líneas y abstracciones. Arquitecturas madrileñas de los '50. Director: Gabriel Ruiz Cabrero. Universidad Politécnica de Madrid, Departamento de Proyectos Arquitectónicos, 2007), 12 (Morales Saro, María Cruz: La arquitectura de Miguel Fisac. Ciudad Real: Colegio de Arquitectos de Ciudad Real, 1979 ); página 129,13 y 14 (Sánchez Lampreave, Ricardo (Ed.): Miguel Fisac. Premio Nacional de Arquitectura 2002. Madrid: Ministerio de Vivienda, 2009); página 130, 15 (Arques Soler, Francisco: Miguel Fisac. Madrid: Pronaos, 1996); página 133, 1 (Ingrid Campo-Ruiz), 2 (464 F6, Flygfoto med bladindelning samma som ekonomisk karta. 1969. [Malmö Stadsbyggnadskontorets Arkiv]); página 134, 3 (205E16, Ekonomisk Karta över Sverige, $2 c$ Malmö Bulltofta. 1969. [Malmö Stadsbyggnadskontorets Arkiv]), 4 (Lewerentz, Sigurd: “Betonghus på Östra Kyrkogården i Malmö”. En Arkitektur. Febrero 1973, N² 2. p. 4), 5 (Lewerentz, Sigurd. Kyrkogårdsförvaltningen, Malmö, Byǵgnad för Blömsterförsäljning vid Östra Kyrkogården i Malmö, Stadsäga nr 199 Rosengård. Plan, sektion, fasader \& situat. plan. Malmo, 2 de diciembre 1968. Malmö kyrkogårdsförvaltning F 1Q:26. [Malmö Stadsarkivet]); página 135, 6 (Flygtrafik i Bengtsfors AB: Vista aérea de Rosengård 1970. Negativo. 13,1 x 18,5 cm, 85976_1157_01. [Lund: Archivo de Kulturen]); página 136, 7 (Ingrid Campo-Ruiz), 8 (Lewerentz, Sigurd. Kyrkogårdsförvaltningen, Malmö, Byǵgnad för Blömsterförsäljning vid Östra Kyrkogården i Malmö, Stadsäga nr 199 Rosengård. Plan, sektion, fasader \& situat. plan. Malmo, 2 de diciembre 1968. Malmö kyrkogårdsförvaltning F 1Q:26. [Malmö Stadsarkivet]); página 137, 9 (Ingrid Campo-Ruiz); página 138, 10 (Lewerentz, Sigurd. Östra Kyrkogården i Malmö, Försäljning av Blömmor, Sektion A-A, D-D Skala 1:20 Detaljer 1:1. Skanör, septiembre, 1968. Malmö kyrkogårdsförvaltning F 1Q:26. [Malmö Stadsarkivet]); página 139, 11 (Ingrid Campo-Ruiz); página 140, 12 y 13 (Ingrid Campo-Ruiz); página 142, 14 (Dibujo 1 (arriba): Lewerentz, Sigurd. Östra Kyrkogården i Malmö, Försäljning av Blömmor, Fasad mot söder. Escala 1:20, detalles 1:1. Skanör, 1 de abril, 1969. Malmö kyrkogårdsförvaltning F 1Q:26. [Malmö Stadsarkivet]. Dibujo 2(abajo): Lewerentz, Sigurd. Östra Kyrkogården i Malmö, Försäljning av Blömmor. Escala 1:20, detalles 1:1. Skanör, septiembre, 1968. Malmö kyrkogårdsförvaltning F 10:26. [Malmö Stadsarkivet]), 15 (Ingrid Campo-Ruiz); página 144, 16 (Blomsteraffären [Kyrkogårdsförvaltningen i Malmö]); página 149, 1 (La Vanguardia. Martes 23 de abril de 1968. Barcelona: Grupo Godó, 1968. p. 46); página 150, 2 (La Vanguardia. Viernes 2 de junio de 1972. Barcelona: Grupo Godó, 1972. p. 2); página 152, 3 (“Edificio industrial para Dallant, S.A.”. En Cuadernos de Arquitectura. № 55. Barcelona: COACB, 1964. p. 5); página 153, 4 (Serrano Freixas, Ángel: “Un edificio diseñado: Banca Catalana, de Tous y Fargas”. En Cuadernos de Arquitectura. № 70, Barcelona: COACB, 1967. p. 26); página 155, 5 y 6 (Serrano Freixas, Ángel: “Un edificio diseñado: Banca Catalana, de Tous y Fargas”. En Cuadernos de Arquitectura. № 70, Barcelona: COACB, 1967. p. 28 y p. 29); página 156, 7 (Pizza, Antonio; Rovira, Josep Maria: Desde Barcelona, Arquitecturas y Ciudad: 1958-1975. Barcelona: Collegi d'Arquitectes de Catalunya - Ministerio de Fomento, 2002. p. 175); página 158, 8 (Montaner, Josep Maria: Arquitectura Contemporánea en Catalunya. Barcelona: Edicions 62, 2006. p. 125) 